\title{
AEROBIC POWER, ANAEROBIC POWER, AND VERTICAL JUMPING ABILITY OVER AN ENTIRE COMPETITIVE PERIOD IN YOUNG ELITE MALE HANDBALL PLAYERS
}

original paper

( ) University School of Physical Education in Wroclaw

DOI: https://doi.org/10.5114/hm.2019.85941

\section{VASILIKI MANOU ${ }^{1}$, JOSE FRANCISCO TORNERO AGUILERA ${ }^{2}$, ATHANASIOS A. DALAMITROS ${ }^{1}$}

${ }^{1}$ Faculty of Physical Education and Sport Sciences, School of Physical Education and Sports Science,

Aristotle University of Thessaloniki, Thessaloniki, Greece

${ }^{2}$ Department of Sport Science, European University of Madrid, Madrid, Spain

\begin{abstract}
Purpose. The purpose of the study was to examine the in-season variations in aerobic power, anaerobic power, and vertical jumping ability in young elite handball players in a laboratory setting.

Methods. The study involved 13 athletes (age: $19.9 \pm 0.7$ years, body mass: $90.0 \pm 12.1 \mathrm{~kg}$, height: $186.3 \pm 6.3 \mathrm{~cm}$, body fat percentage: $13.7 \pm 4.8 \%)$, all members of the young national handball team. Maximal oxygen uptake $\left(\mathrm{VO}_{2} \mathrm{max}\right)$, Wingate Anaerobic Test (WAnT) performance (peak power [PP], mean power [MP], fatigue index [FI]), and vertical jumping ability (countermovement jump [CMJ]) were assessed on 3 occasions during the competitive period (beginning [T1], middle [T2], end [T3]).

Results. Only slight and not significant changes were observed throughout the tested period for $\mathrm{VO}_{2} \mathrm{max}(\mathrm{T} 1=52.04 \pm 4.30$; $\mathrm{T} 2=49.31 \pm 3.96 ; \mathrm{T} 3=51.68 \pm 5.38 \mathrm{ml} \cdot \mathrm{kg}^{-1}$; T1 to T3: $\left.-0.24 \pm 5.83 \%, p>0.05\right)$ and CMJ values $(\mathrm{T} 1=46.99 \pm 7.98$; $\mathrm{T} 2=46.57 \pm 5.87 ; \mathrm{T} 3=48.15 \pm 6.58 \mathrm{~cm}$; T1 to T3: $-3.26 \pm 6.88 \%, p>0.05)$. Similarly, all parameters evaluated during the WAnT showed small variations (PP: T1 to T3: $1.11 \pm 5.67 \%$; MP: T1 to T3: $-0.04 \pm 4.34 \%$; FI: T1 to T3: $3.43 \pm 9.20 \%$; $p>0.05$ ). Conclusions. The indices of aerobic power, anaerobic power, and vertical jumping ability remained relatively constant among the tested group of young elite athletes throughout the handball competitive period.
\end{abstract}

Key words: fitness profile, seasonal changes, handball

\section{Introduction}

Handball is a high-intensity intermittent exercise activity with specific physiological demands. While anaerobic capacity is a key performance indicator, aerobic power is also of high importance; the requirements of the aerobic energy system are characterized as moderate to high [1], with the consideration of the long period of an average game ( 2 halves, each of $30 \mathrm{~min}$ of efficient playing time). A large emphasis is also placed on jumping activities, bound with high muscular power requirements, especially for the lower extremities [2]. This diversity of efforts necessitates a comprehensive preseason preparation, including the improvement of aerobic power, anaerobic power, and explosiveness, as well as control of possible variations during the entire competitive season.

Most of the previous handball studies involving male subjects have focused on describing several parameters defining the anthropometrical and physiological characteristics for elite performance [1, 3, 4]. Other authors have examined the effect of short-term specific training programs [5], or analysed physiological changes during specific periods of an annual macrocycle [6, 7]. Regarding a more comprehensive evaluation including an entire competitive season, strength values of the upper and lower extremities, explosive strength, as well as sprint and endurance run-

Correspondence address: Athanasios A. Dalamitros, Faculty of Physical Education and Sport Sciences, Aristotle University of Thessaloniki, Thermi Thessalonikis, 57001, Thessaloniki, Greece, e-mail: dalammi@phed.auth.gr

Received: March 19, 2019

Accepted for publication: May 21, 2019

Citation: V. Manou, J.F.T. Aguilera, A.A. Dalamitros. Aerobic power, anaerobic power, and vertical jumping ability over an entire competitive period in young elite male handball players. Hum Mov. 2019;20(4):28-32; doi: https://doi.org/10.5114/ hm.2019.85941. 
ning have been evaluated in 2 cases under field conditions [2, 8].

Despite the greater evaluation specificity characterizing field testing, laboratory tests are considered more accurate and appropriate in the assessment of general fitness during specific periods of the season [9]. In addition, more information can be obtained when conducting a single-laboratory test; for instance, during the 30-s Wingate Anaerobic Test (WAnT), different components of an athletes' anaerobic capacity can be evaluated [10]. Thus, our purpose was to examine the effect of the preseason, in-season, and end of the competitive period on the comprehensive fitness profile, including the assessment of aerobic power, anaerobic power, and jumping ability in a laboratory setting in a group of elite male handball players. Based on previous observations, our hypothesis was that the variables tested would only show trivial changes throughout the specific period.

\section{Material and methods}

\section{Participants}

Overall, 13 athletes volunteered to participate in this study (mean $\pm S D$; age: $19.9 \pm 0.7$ years, body mass: $90.0 \pm 12.1 \mathrm{~kg}$, height: $186.3 \pm 6.3 \mathrm{~cm}$, percentage of body fat: $13.7 \pm 4.8 \%$ ). All players were members of the Greek national handball team and were familiarized with the testing procedures before the beginning of the experimental phases. All tests were performed under controlled environmental conditions (temperature: $20-22^{\circ}$, relative humidity: ca. 45\%), at the same time of the day (9:00-12:00).

\section{Procedure}

In order to examine the in-season variations in aerobic power, anaerobic power, and vertical jumping ability, the following testing procedures were conducted: maximal oxygen uptake $\left(\mathrm{VO}_{2} \max \right)$ determination, WAnT, and countermovement jump (CMJ). Each testing procedure was assessed on 3 occasions during the entire 9-month competitive period (beginning, August [T1]; middle, January [T2]; end, May [T3]).

At the beginning of each testing session, body mass and height were measured to the nearest $0.1 \mathrm{~kg}$ and $0.1 \mathrm{~cm}$, respectively, by using calibrated physician's scales (Seca, Hamburg, Germany). The percentage of body fat was estimated with the bioelectrical impedance analysis technique (Bodystat 1500; Bodystat, Isle of Man, British Isles). Afterward, the participants completed a standardized 7-min warm-up on a stationary cycle-ergometer (Technogym) with pedalling cadence visually controlled at $50-60 \mathrm{rpm}$ and $5 \mathrm{~min}$ of stretching exercises.

$\mathrm{VO}_{2}$ max was determined during an incremental treadmill test by using a standard laboratory metabolic chart. Breath-by-breath analysis was applied for measuring respiratory gas exchange (Cosmed Quark CPET system, Rome, Italy) throughout the test. Heart rate (HR) was continuously evaluated and recorded with an electronic HR monitor (Polar S610 Electro, Kempele, Finland). $\mathrm{O}_{2}$ and $\mathrm{CO}_{2}$ analysers were calibrated before and after each test with ambient air and calibration gas of known concentrations. Verbal encouragement was given throughout each test. The initial speed was set at $8 \mathrm{~km} \cdot \mathrm{h}^{-1}$ and was increased steadily by $1 \mathrm{~km} \cdot \mathrm{h}^{-1}$ every 2 minutes until volitional exhaustion. Effort test was considered as valid when at least 2 of the following criteria were achieved: (i) not less than 15 beats below age-predicted maximal HR, (ii) levelling off of $\mathrm{VO}_{2}$ despite an increase in workload, (iii) maximal respiratory exchange ratio $>1.10$ [11]. Gas exchange data were averaged over 15-s periods. $\mathrm{VO}_{2} \max$ was considered the single highest $15-\mathrm{s} \mathrm{VO}_{2}$ value attained.

Anaerobic power was measured with the 30-s WAnT, following previous methodology [10]. The testing procedure was performed on a cycle-ergometer (Ergomedic $874 \mathrm{e}$, Monark, Sweden). The braking force was settled by the product of body mass in $\mathrm{kg}$ by $0.075 \%$. The seat height was adjusted to each player needs; toe clips were also used in order to prevent any possible slipping off the pedals and to assure maximum efficacy and efficiency. Athletes were asked before the initiation of the test to pedal as fast as possible and were vigorously encouraged during the entire test. The duration of every flywheel revolution during the test was measured with the help of an electronic sensor, whereas the power output of every revolution was computed by specialized software (SMI, St. Cloud, USA).

For the evaluation of the lower limbs explosiveness, flight time and jump height were estimated by using the Optojump photocell system (Microgate, Bolzano, Italy). The participants were requested to maximally perform 3 CMJs with an arm swing (CMJ). A 1-min rest took place between efforts. The single highest score was used for further analysis.

\section{Statistical analysis}

The SPSS statistical package (version 22.0; SPSS, Inc., Chicago, USA) was applied to analyse the data. 
Mean and standard deviation $(S D)$ values were calculated with traditional statistical techniques. Normality and homoscedasticity assumptions were checked with the Kolmogorov-Smirnov test. To analyse possible changes in intra-seasonal points and to compare the different stages of preparation, an ANOVA test was used for all the variables. Data are presented as means $\pm S D$. The level of statistical significance was set as $\alpha=0.05$.

\section{Ethical approval}

The research related to human use has complied with all the relevant national regulations and institutional policies, has followed the tenets of the Declaration of Helsinki, and has been approved by the authors' institutional review board or an equivalent committee.

\section{Informed consent}

Informed consent has been obtained from all individuals included in this study.

\section{Results}

The results are presented in Table 1. Only slight and not significant changes throughout the tested periods for $\mathrm{VO}_{2}$ max were obtained $(\mathrm{T} 1=52.04 \pm 4.30$; $\mathrm{T} 2=$ $49.31 \pm 3.96$; $\left.\mathrm{T} 3=51.68 \pm 5.38 \mathrm{ml} \cdot \mathrm{kg}^{-1}\right)$. Regarding the $\mathrm{CMJ}$ values, small variations between periods were observed $(\mathrm{T} 1=46.99 \pm 7.98 ; \mathrm{T} 2=46.57 \pm 5.87 ; \mathrm{T} 3=$ $48.15 \pm 6.58 \mathrm{~cm})$. Peak anaerobic power showed an increase of $1.11 \pm 5.67 \%$ between $\mathrm{T} 1$ and $\mathrm{T} 3$, while the respective value for mean anaerobic power was $-0.04 \pm 4.34 \%$. Finally, the fatigue index was $3.43 \pm$ $9.20 \%$. All presented values had a $p>0.05$ level of significance.

\section{Discussion}

To our knowledge, this is the first study presenting variations of the comprehensive fitness profile observed during an entire competitive season in an elite national handball team in a laboratory setting. The results suggest that the evaluated selected indices of aerobic power, anaerobic power, and vertical jumping ability remained relatively constant throughout the handball period tested. These data can provide useful information for both athletes and practitioners regarding physiological adaptations as a result of an entire handball training period.

Specific physiological performance variables of male athletes from different team sports such as basketball $[12]$ and soccer $[13,14]$ tend to remain constant throughout a competitive season. Similar results for handball players were demonstrated by Gorostiaga et al. [2], reporting no significant seasonal variations in lower extremity strength values in male high-level handball players. Likewise, Boraczyński and Urniaż [5] revealed no significant improvement in anaerobic power values assessed during WAnT, also in high-level handball athletes. In contrast, the above-mentioned study reported significant increases in absolute $\mathrm{VO}_{2}$ max values (approximately 7\%), which can probably be attributed to the fact that the corresponding values were significantly lower, during both periods tested, compared with those presented in the current study.

Aerobic power, as reflected by the $\mathrm{VO}_{2}$ max values, showed a slight increment of ca. $1.0 \%$ over the entire season. Angius et al. [15] support this result, indicating that adult athletes present a fully developed aerobic capacity; therefore, only slight changes would be expected. In addition, one of the main targets of the preseason period is to elevate the aerobic fitness component and to maintain its high level during the entire season.

Table 1. Mean and standard deviation values for all variables tested during the 3 season periods

\begin{tabular}{lrrrrrrrrr}
\hline \multirow{2}{*}{ Variable } & \multicolumn{3}{c}{$\mathrm{T} 1$} & \multicolumn{2}{c}{$\mathrm{T} 2$} & \multicolumn{2}{c}{$\mathrm{T} 3$} \\
\cline { 2 - 9 } & \multicolumn{1}{c}{ Value } & \multicolumn{1}{c}{$p$} & $\mathrm{~F}$ & Value & \multicolumn{1}{c}{$p$} & $\mathrm{~F}$ & Value & \multicolumn{1}{c}{$p$} \\
\hline $\mathrm{VO}_{2} \mathrm{max}\left(\mathrm{ml} \cdot \mathrm{kg}^{-1}\right)$ & $50.6 \pm 6.7$ & 0.10 & 2.528 & $48.8 \pm 4.3$ & 0.11 & 2.528 & $51.1 \pm 5.9$ & 0.10 & 2.528 \\
$\mathrm{PP}\left(\mathrm{W} \cdot \mathrm{kg}^{-1}\right)$ & $12.2 \pm 1.2$ & 0.11 & 2.449 & $12.4 \pm 1.1$ & 0.12 & 2.449 & $12.0 \pm 1.3$ & 0.11 & 2.449 \\
$\mathrm{MP}\left(\mathrm{W} \cdot \mathrm{kg}^{-1}\right)$ & $9.0 \pm 0.5$ & 0.14 & 2.128 & $9.2 \pm 0.6$ & 0.16 & 2.128 & $9.0 \pm 0.5$ & 0.16 & 2.128 \\
$\mathrm{FI}(\%)$ & $45.3 \pm 4.3$ & 0.20 & 1.732 & $45.1 \pm 5.8$ & 0.21 & 1.732 & $43.1 \pm 7.5$ & 0.20 & 1.732 \\
$\mathrm{CMJ}(\mathrm{cm})$ & $46.9 \pm 7.9$ & 0.12 & 2.324 & $46.5 \pm 5.8$ & 0.13 & 2.324 & $48.1 \pm 6.8$ & 0.12 & 2.324 \\
\hline
\end{tabular}

T1 - beginning of the competitive period, T2 - middle of the competitive period, T3 - end of the competitive period, $\mathrm{VO}_{2} \mathrm{max}$ - maximal oxygen uptake, $\mathrm{PP}$ - relative peak power, $\mathrm{MP}$ - relative mean power, $\mathrm{FI}$ - fatigue index,

$\mathrm{CMJ}$ - countermovement jump with an arm swing. 
Data analysis regarding the anaerobic testing procedure revealed a slight reduction of $-1.64 \%$ in peak relative anaerobic power values and a larger decrease of $-4.86 \%$ for fatigue index. In contrast, no variations were observed for mean anaerobic power values. A previous study reported that anaerobic performance tended to decrease during the competitive season, as our study suggests, in rugby players [16]. According to Dupont et al. [17], anaerobic performance, expressed in terms of high-intensity sprints, can be enhanced during the in-season period, following a specific training program in male soccer players. Additionally, repeated sprint ability $(4 \times 60 \mathrm{~m})$ was improved after an in-season 10 -week training period, also in soccer [18]. Even though related data are only available in soccer, a specific training program aiming to develop in-season anaerobic performance in handball is proposed.

Explosiveness of the lower limbs was measured in this study through the countermovement vertical jump test, demonstrating no significant increase (2.56\%). Gorostiaga et al. [2] confirm this result, reporting vertical jumping ability in a sample of elite handball players. In our study, no significant improvement was found in any of the variables evaluated during WAnT, which is in agreement with the study by Boraczyński and Urniaż [5], also confirming the respective values. The mean jumping height of our participants $(46.9 \pm 7.9 \mathrm{~cm})$ was significantly higher than the previous result obtained in an elite male handball team in the study by Milanez et al. [7] (42.4 $\pm 3.8 \mathrm{~cm})$, but comparable to that reported by Gorostiaga et al. [2] (45.2 \pm 7.0 to $48.2 \pm 7.2 \mathrm{~cm}$ ). However, caution should be paid when interpreting data from different studies, as the initial competitive level of participants, the training program applied, as well as the specific period of testing and other methodological issues can affect the results.

An obvious limitation can be addressed regarding the relatively small sample size. Nevertheless, all participants in this study were considered as high-level athletes, composing the national handball team, a fact that can also be referred to as one of the study strengths. While the improvement of general fitness is essential during the preseason period, competitive success also depends on tactical preparation and technical ability. Thus, the absence of a sports-specific testing procedure resembling handball-specific activity patterns during the different season periods (e.g. agility test) consists a second limitation in this study. Although all participants were members of clubs form the First Division with similar training background, it is logical to expect that different training programs were followed during the tested period.

\section{Conclusions}

In summary, we observed that the comprehensive fitness profile evaluated by laboratory tests in this study, including the measurement of aerobic power, anaerobic power, and vertical jumping ability, during 3 different occasions (the beginning, middle, and end of the competitive period) revealed relatively constant values for all the parameters in the investigated group of elite male handball athletes. Since the maintenance of physical fitness level during the season is the key target in team sports, frequent testing can be a supplementary tool for coaches and strength and conditioning professionals to identify possible signs of overtraining. Finally, the data presented here can be used as physical fitness standards for professional handball players.

\section{Acknowledgements}

The authors would like to thank the athletes who contributed their time in this research. No outside funding was received for this work.

\section{Disclosure statement}

No author has any financial interest or received any financial benefit from this research.

\section{Conflict of interest}

The authors state no conflict of interest.

\section{References}

1. Michalsik LB, Madsen K, Aagaard P. Physiological capacity and physical testing in male elite team handball. J Sports Med Phys Fitness. 2015;55(5):415-429.

2. Gorostiaga EM, Granados C, Ibañez J, González-Badillo JJ, Izquierdo M. Effects of an entire season on physical fitness changes in elite male handball players. Med Sci Sports Exerc. 2006;38(2):357-366; doi: 10.1249/01.mss.0000184586.74398.03.

3. Chaouachi A, Brughelli M, Levin G, Boudhina NB, Cronin J, Chamari K. Anthropometric, physiological and performance characteristics of elite team-handball players. J Sports Sci. 2009;27(2):151-157; doi: 10.1080/02640410802448731.

4. Ziv G, Lidor R. Physical characteristics, physiological attributes, and on-court performances of handball players: a review. Eur J Sport Sci. 2009;9(6):375-386; doi: 10.1080/17461390903038470.

5. Boraczyński T, Urniaż J. Changes in aerobic and anaerobic power indices in elite handball players following a 4-week general fitness mesocycle. J Hum Kinet. 2008;19:131-139; doi: 10.2478/v10078-008-0010-1.

6. Cular D. Half season changes in physical fitness for the high level handball players. Res Phys Educ Sport Health. 2013;2(1):35-42. 


\section{HUMAN MOVEMENT}

V. Manou, J.F.T. Aguilera, A.A. Dalamitros, Seasonal changes in elite handball

7. Milanez VF, Ramos SP, Leprêtre PM, Leme LC, Nakamura FY. Physiological and performance changes in response to pre-season in high level handball players. Sci Sports. 2014;29(4):e59-e62; doi: 10.1016/j.scispo. 2014.03.003.

8. Pavlović L, Bojić I, Stojiljković N, Djordjević D, Radovanović $\mathrm{D}$. Seasonal changes in selected physical and physiological variables in male handball players. Acta Fac Med Naiss. 2018;35(3):226-235; doi: 10.2478/ afmnai-2018-0024.

9. Svensson M, Drust B. Testing soccer players. J Sport Sci. 2005;23(6):601-618; doi: 10.1080/026404104000 21294.

10. Inbar O, Bar-Or O, Skinner JS. The Wingate anaerobic test. Champaign: Human Kinetics; 1996.

11. Larsen GE, George JD, Alexander JL, Fellingham GW, Aldana SG, Parcell AC. Prediction of maximum oxygen consumption from walking, jogging, or running. Res Q Exerc Sport. 2002;73(1):66-72; doi: 10.1080/02701367. 2002.10608993.

12. Hoffman JR, Fry AC, Howard R, Maresh CM, Kraemer WJ. Strength, speed and endurance changes during the course of a Division I basketball season. J Strength Cond Res. 1991;5(3):144-149; doi: 10.1519/1533-4287 (1991)005<0144:ssaecd>2.3.co;2.

13. Kalapotharakos VI, Ziogas G, Tokmakidis SP. Seasonal aerobic performance variations in elite soccer players. J Strength Cond Res. 2011;25(6):1502-1507; doi: 10.1519/JSC.0b013e3181da85a9.

14. Silvestre R, Kraemer WJ, West C, Judelson DA, Spiering BA, Vingren JL, et al. Body composition and physical performance during a National Collegiate Athletic Association Division I men's soccer season. J Strength CondRes.2006;20(4):962-970; doi:10.1519/R-18165.1.

15. Angius L, Olla S, Pinna M, Mura R, Marongiu E, Roberto $S$, et al. Aerobic and anaerobic capacity of adult and young professional soccer players. Sport Sci Health. 2012;8(2-3):95-100; doi: 10.1007/s11332-012-0133-6.

16. Argus CK, Gill N, Keogh J, Hopkins WG, Beaven CM. Effects of a short-term pre-season training programme on the body composition and anaerobic performance of professional rugby union players. J Sports Sci. 2010; 28(6):679-686; doi: 10.1080/02640411003645695.

17. Dupont G, Akakpo K, Berthoin S. The effect of in-season, high-intensity interval training in soccer players. J Strength Cond Res. 2004;18(3):584-589; doi: 10.1519/ 1533-4287(2004)18<584:TEOIHI>2.0.CO;2.

18. Nedrehagen ES, Saeterbakken AH. The effects of inseason repeated sprint training compared to regular soccer training. J Hum Kinet. 2015;49:237-244; doi: 10.1515/hukin-2015-0126. 